\title{
Dehydroepiandrosterone modifies rat fatty acid composition of serum and different adipose tissue depots and lowers serum insulin levels
}

\author{
Fátima Pérez de Heredia, Elvira Larqué, Salvador Zamora and Marta Garaulet \\ Department of Physiology, University of Murcia, Murcia, 30100 Spain \\ (Correspondence should be addressed to M Garaulet who is now at Paseo Rector Sabater s/n, Facultad de Biología, Campus de Espinardo, 30100 Murcia, Spain; \\ Email: garaulet@um.es)
}

\begin{abstract}
Dehydroepiandrosterone (DHEA) is reported to exert beneficial effects, such as protection from cardiovascular risk and lowering serum insulin levels. Adipose tissue (AT) is a target for DHEA actions, and the hormone can also affect hepatic fatty acid (FA) metabolism. FAs are involved in the development of insulin resistance; thus, there might be a relationship between DHEA, FA, and insulin. However, few data are available regarding DHEA and FA composition, especially concerning AT. Seventeen-month old female Sprague-Dawley rats $(n=11$; controls: $n=10)$ were treated with DHEA $(0 \cdot 5 \% \mathrm{w} / \mathrm{w}$ in the diet) for 13 weeks, after which serum, periovarian, mesenteric, s.c., and brown AT were analyzed for FA composition. DHEA treatment resulted in significant changes in FA profiles in serum and adipose depots, like reduced $16: 1 n-7$ (s.c. and brown AT; $P<0 \cdot 01$ ), elevated n-9 monounsaturated FA (serum and s.c. AT;
\end{abstract}

$P<0 \cdot 05)$, diminished $n-6$ polyunsaturated FA (PUFA; general; $P<0 \cdot 05$ ) and increased $n-3$ PUFA (brown AT; $P<0 \cdot 01$ ), along with lower $n-6 / n-3$ ratios (s.c. and brown AT; $P<0.05, \quad P<0 \cdot 01$ respectively). DHEA modified estimates of desaturase activities, decreasing stearoyl-CoAdesaturase markers in s.c., and brown AT $(P<0 \cdot 05)$ and increasing those of delta-6-desaturase in serum and AT $(P<0 \cdot 05)$. In addition, DHEA-treated rats showed lower serum insulin levels $(P<0 \cdot 05)$. We have demonstrated for the first time that DHEA induces significant modifications in AT fatty acid composition in vivo, mainly concerning unsaturated FAs, and changes occurred in a tissue-dependent manner. We propose that these changes may be related to the capacity of DHEA to lower serum insulin levels.

Journal of Endocrinology (2009) 201, 67-74

\section{Introduction}

The steroid hormone dehydroepiandrosterone (DHEA) and its sulphated form (DHEA-S) are known as precursors for most sexual hormones, both androgens and estrogens (Regelson et al. 1994), but they have also been shown to exert several positive effects themselves, independently of their conversion into androgens or estrogens, and there is even evidence for specific receptors for DHEA (Liu \& Dillon 2004).

DHEA and DHEA-S show a marked decline in their serum levels with advancing age (Arlt 2004). Besides, low serum concentrations of these hormones, they have been associated with certain pathological states that increase their prevalence during ageing. Among the beneficial effects of DHEA, we can find cancer prevention (Ratko et al. 1991, Kawai et al. 1995), amelioration of cognitive function (Yanase et al. 1996), or protection against cardiovascular disease (Ebeling \& Koivisto 1994), atherosclerosis (Nestler et al. 1992), or obesity (Richards et al. 2000, Abadie et al. 2001, de Heredia et al. 2007). Improvement of peripheral insulin sensitivity has also emerged as one of DHEA's relevant actions; indeed, we and other authors have previously observed that DHEA administration to rodents reduced significantly serum insulin concentrations (Richards et al. 2000, Abadie et al. 2001, Sánchez et al. 2008).

Adipose tissue (AT) seems to be one of the main targets in DHEA and DHEA-S actions. It has been reported that these steroids reduce AT cellularity (Ryu et al. 2003), inhibit preadipocyte differentiation in vitro (Lea-Currie et al. 1998), stimulate lipolysis (Tagliaferro et al. 1995, HernándezMorante et al. 2008), and alter AT gene expression (Kajita et al. 2003, Sánchez et al. 2008). In addition, DHEA-S can modulate fatty acid (FA) metabolism, through up-regulation of hepatic enzymes involved in $\beta$-oxidation (Waxman 1996, Depreter et al. 2002).

The relevance of FAs is far beyond their role as energy storage molecules in AT, and they are recognized as important metabolic effectors (Yaqoop 2002, Drevon 2005, Steinberg 2007). FAs act as transcriptional modulators, regulating the expression of genes involved in energy metabolism or AT function (Raclot et al. 1997, Wilding 2001). Of particular concern is their impact on the development of insulin resistance (Kraegen et al. 2001, Russell 2004, Saravanan et al. 2005), and research is constantly demonstrating that the 
nature of FAs present in the different tissues is as important as their total amount in relation to the development of metabolic alterations (Garaulet et al. 2001). Consequently, the proportions in which FAs appear in AT may have a great relevance in the physiology of this tissue, in particular regarding the sensitivity to insulin stimulation.

The relationships among DHEA, FAs, and insulin sensitivity suggest that FAs could be mediators in the insulin-sensitizing actions of the hormone. Despite this fact, little is known about the effects of DHEA on FA composition in different tissues (Abadie et al. 2001, Imai et al. 2001, Gómez et al. 2002), and no studies to our knowledge have shown significant changes in AT fatty acid profile due to DHEA action.

Considering all this information, we aimed to study the effect of a pharmacological dose of DHEA on FA composition in serum and different AT depots in an animal model prone to metabolic disturbances, i.e., ageing rats fed on a high-energy saturated-fat diet. In the present work, we found that the hormonal treatment resulted in significant changes in the FA profiles of serum, of visceral and s.c. white AT and of brown AT, and propose that these changes can be related to the insulin-sensitizing action of DHEA.

\section{Materials and Methods}

\section{Animals and conditions}

Twenty-one female Sprague-Dawley rats, provided by the animal care facilities of the University of Murcia, were kept in a temperature-controlled room $\left(24 \pm 2{ }^{\circ} \mathrm{C}\right)$ in a $12 \mathrm{~h}$ light: $12 \mathrm{~h}$ darkness schedule with lights on at $0800 \mathrm{~h}$. Water and food were always provided ad libitum. The animal protocol followed in this study was reviewed and approved by the bioethical committee of our university and guidelines for the use and care of laboratory animals of the university were followed.

From 7 weeks of age, animals were fed on a hypercaloric diet that consisted on $200 \mathrm{~g} / \mathrm{kg}$ casein (Hero, Murcia, Spain), $245 \mathrm{~g} / \mathrm{kg}$ corn starch (Hero), $244 \mathrm{~g} / \mathrm{kg}$ sucrose (local market), $200 \mathrm{~g} / \mathrm{kg}$ palm oil (Croexsa, Barcelona, Spain), $50 \mathrm{~g} / \mathrm{kg}$ cellulose (Avicel, Barcelona, Spain), $2 \mathrm{~g} / \mathrm{kg}$ choline $\mathrm{HCl}$ (J Escuder, Barcelona, Spain), and $4 \mathrm{~g} / \mathrm{kg}$ methionine (J Escuder); vitamin $(10 \mathrm{~g} / \mathrm{kg})$ and mineral $(45 \mathrm{~g} / \mathrm{kg})$ mixes were formulated according to AIN-93 guidelines (Reeves et al. 1993) and were supplied by Tegasa (Valencia, Spain) and Sigma. This diet contained (expressed as a percentage of fresh mass) $18 \cdot 4 \%$ protein, $50 \cdot 4 \%$ carbohydrates (50\% of which was sucrose), and $19 \cdot 6 \%$ fat, with an energy content of $1880 \mathrm{~kJ} /$ $100 \mathrm{~g}$; in terms of energy fat accounted for 39\% total dietary energy. FA composition of dietary fat was $53 \cdot 6 \%$ saturated FAs (SFA), 36.3\% monounsaturated FAs (MUFA), 9.5\% polyunsaturated FAs (PUFA) and $0 \cdot 6 \%$ trans FAs (Pérez de Heredia et al. 2008). The diet was prepared once a week in our laboratory and stored at $5{ }^{\circ} \mathrm{C}$ in order to avoid rancidity, and food was freshly dispensed every other day.

\section{DHEA treatment}

At the age of 17 months, rats were divided into two groups: one received the diet supplemented with DHEA (Roig Farma, S.A., Terrasa, Barcelona, 99.5\% purity) at a concentration of $0.5 \%$ (5 $\mathrm{g} \mathrm{DHEA} / \mathrm{kg}$ diet) (DHEA group, $n=11$ ), while the rest of the animals continued without changes and served as controls (control group, $n=10$ ). The hormonal treatment lasted for 13 weeks, when rats were 20 months old.

\section{Sample collection}

In the beginning of the light phase and following overnight fast, rats were weighed and killed under anesthesia (ether). Blood samples were collected by cardiac puncture, immediately centrifuged $15 \mathrm{~min}$ at $1500 \mathrm{~g}$ and $4^{\circ} \mathrm{C}$, and serum was stored at $-80{ }^{\circ} \mathrm{C}$ until analyzed. White AT from visceral (periovarian and mesenteric) and s.c. (abdominal region) depots, and interscapular brown AT were removed, weighed, immediately frozen in liquid nitrogen, and stored at $-80^{\circ} \mathrm{C}$.

In serum, insulin levels and the homeostatic model assessment (HOMA-IR index) were determined as previously described (Sánchez et al. 2008). Briefly, serum insulin was measured by RIA, using a commercial kit (Linco, St Charles, MO, USA), and serum glucose was measured by spectrophotometry using an enzymatic kit with glucoseoxidase and peroxidase. The HOMA-IR index was then calculated with the following formula (Matthews et al. 1985): HOMA-IR $=$ Fasting glucose $(\mathrm{mmol} / \mathrm{l}) \times$ fasting insulin $(\mathrm{mIU} / 1) / 22 \cdot 5$.

\section{Determination of FA composition}

Total lipids from serum and AT samples were extracted according to the method of Folch et al. (1957), previous addition of an internal standard (tridecanoic acid, C13:0). FA methyl esters (FAME) were prepared with methanol HCl $3 \mathrm{M}$ (Supelco, Bellefonte, PA, USA) at $100{ }^{\circ} \mathrm{C}$ for $1 \mathrm{~h}$ and dissolved in hexane. FAME were analyzed in a gas chromatograph HP-6890 (Agilent Technologies, Inc. Palo Alto, CA, USA), using a column SP-2560 of $60 \mathrm{~m} \times$ $0 \cdot 25 \mathrm{~mm}$ id $\times 0 \cdot 15 \mu \mathrm{m}$ (Supelco, SIGMA-Aldrich). The oven temperature was programmed at an initial temperature of $175^{\circ} \mathrm{C}$ and after $30 \mathrm{~min}$ it was increased at a rate of $7^{\circ} \mathrm{C} /$ $\min$ to $230{ }^{\circ} \mathrm{C}$ for $20 \mathrm{~min}$. The injector and detector were set at $240{ }^{\circ} \mathrm{C}$. Helium was used as the carrier gas at a pressure of $290 \mathrm{kPa}$. Peaks were identified by comparison of their retention times with appropriate FAME standards purchased from Sigma Chemical (SIGMA-Aldrich).

The amount of each individual FA was calculated and expressed as a percentage of total lipids FAs present in the samples. Then, total SFA were calculated as the sum of 
12:0, 14:0, 15:0, 16:0, 17:0, 18:0, 20:0, 21:0, 22:0, 23:0, and 24:0; total MUFA were calculated as the sum of 14:1 n-9, 16:1 $n-9,17: 1 n-9,18: 1 n-9,20: 1 n-9,22: 1 n-9,24: 1 n-9,16: 1$ $n-7$, and 18:1 n-7; n-6 PUFA were obtained from 18:2 n-6, 18:3 n-6, 20:2 n-6, 20:3 n-6, 20:4 n-6, 22:2 n-6, 22:4 n-6, and 22:5 n-6; $n-3$ PUFA were calculated from 18:3 n-3, 18:4 n-3, 20:3n-3, 20:5 n-3, 22:5n-3, and 22:6n-3; finally, trans FAs were calculated as the sum of C16:1 trans, C18:1 trans, C18:2 cis, trans, C18:2 trans, cis and, C18:2 trans, trans.

\section{Statistical analysis}

Results are presented as mean \pm s.E.M. Comparisons of FA proportions between control and DHEA groups were analyzed by the Student's $t$-test. To determine whether the effect of DHEA treatment on FA composition was tissuespecific, a two-way ANOVA test was also performed for AT depots, followed by Bonferroni post-hoc correction. Significance was always set at $P<0 \cdot 05$. All analyses were performed using the statistic software SPSS v13.0 (SPSS Inc, Chicago, IL, USA).

\section{Results}

According to the average food intake, rats in the DHEA group received an estimated average dose of $6.8 \mathrm{mg}$ DHEA/rat per day. After 13 week treatment, these animals had significantly higher serum DHEA-S levels than their controls $(829.6 \pm 93.3$ and $71 \cdot 8 \pm 26.0 \mathrm{ng} / \mathrm{ml}$ respectively; $P<0 \cdot 001)$. In addition, DHEA-treated rats showed lower serum insulin levels than control ones $(42 \cdot 2 \pm 7 \cdot 5$ and $79 \cdot 3 \pm$ $16.4 \mathrm{pmol} / 1$ respectively, $P=0.047)$, and a tendency to a lower HOMA-IR index $(1.9 \pm 0.3$ and $3.5 \pm 1.00$ respectively, $P=0 \cdot 154)$.

In serum from DHEA-treated rats, MUFA percentages were higher, while $n-6$ and $n-3$ PUFA were lower than in the control group (Table 1). Trans FAs were similar between groups, and so were total SFA, although with increased 16:0 and decreased 18:0 proportions in the DHEA group, which explain the apparent stability of total SFA (Table 1).

Tables 2 and 3 contain the FA profile of the periovarian and mesenteric ATs -both visceral depots- respectively. N-6 PUFA proportions were significantly lower in rats that received DHEA, mainly due to a reduction on 18:2 n-6, while 20:4 n-6 was increased, pointing toward a higher delta6-desaturase activity.

In the s.c. AT, changes were more pronounced (Table 4). Total proportions of $n-9$ MUFA, trans FAs and 20:5 n-3 were higher in the DHEA group, while $n-6$ PUFA were again lower, leading to significantly diminished $n-6 / n-3$ PUFA ratio. It is important to remark the reduction in the percentages of 16:1 n-7 by DHEA treatment, since it has been suggested as a potential marker of metabolic syndrome (Gil-Campos et al. 2008, Paillard et al. 2008). This decrease in 16:1 n-7 was also observed in the interscapular brown AT of
Table 1 Selected fatty acids in serum from experimental groups

\begin{tabular}{|c|c|c|c|}
\hline \multirow[b]{2}{*}{ Fatty acids (\%) } & Control $(n=10)$ & DHEA $(n=10)$ & \multirow[t]{2}{*}{$\boldsymbol{P}$} \\
\hline & & & \\
\hline $12: 0$ & $0 \cdot 21 \pm 0 \cdot 102$ & $0 \cdot 32 \pm 0 \cdot 208$ & NS \\
\hline 14:0 & $0 \cdot 83 \pm 0 \cdot 452$ & $0 \cdot 48 \pm 0 \cdot 081$ & NS \\
\hline 16:0 & $18 \cdot 20 \pm 1 \cdot 278$ & $22 \cdot 72 \pm 1 \cdot 089$ & $0 \cdot 015$ \\
\hline 18:0 & $12 \cdot 97 \pm 0 \cdot 658$ & $8 \cdot 72 \pm 0 \cdot 428$ & $<0.001$ \\
\hline $16: 1 n-9$ & $0 \cdot 25 \pm 0 \cdot 016$ & $0 \cdot 42 \pm 0 \cdot 041$ & $0 \cdot 003$ \\
\hline $16: 1 n-7$ & $1 \cdot 03 \pm 0 \cdot 096$ & $0 \cdot 78 \pm 0 \cdot 077$ & $0 \cdot 055$ \\
\hline $18: 1 n-9$ & $15 \cdot 14 \pm 1 \cdot 000$ & $22 \cdot 15 \pm 1 \cdot 395$ & $0 \cdot 001$ \\
\hline $18: 1 n-7$ & $1 \cdot 40 \pm 0 \cdot 101$ & $1 \cdot 51 \pm 0 \cdot 080$ & NS \\
\hline $18: 2 n-6$ & $7 \cdot 31 \pm 0 \cdot 207$ & $5 \cdot 85 \pm 0 \cdot 446$ & $0 \cdot 008$ \\
\hline $18: 3 n-6$ & $0 \cdot 48 \pm 0.036$ & $0 \cdot 59 \pm 0.045$ & $0 \cdot 056$ \\
\hline $20: 2 n-6$ & $0 \cdot 19 \pm 0 \cdot 062$ & $0 \cdot 49 \pm 0 \cdot 129$ & 0.053 \\
\hline $20: 3 n-6$ & $0 \cdot 33 \pm 0 \cdot 039$ & $0 \cdot 56 \pm 0 \cdot 059$ & $0 \cdot 006$ \\
\hline $20: 4 n-6$ & $32 \cdot 74 \pm 1 \cdot 549$ & $27 \cdot 41 \pm 1 \cdot 534$ & $0 \cdot 025$ \\
\hline $22: 5 n-6$ & $1 \cdot 93 \pm 0 \cdot 204$ & $0 \cdot 80 \pm 0 \cdot 080$ & $<0 \cdot 001$ \\
\hline $18: 3 n-3$ & $0 \cdot 41 \pm 0 \cdot 179$ & $0 \cdot 44 \pm 0 \cdot 181$ & NS \\
\hline $18: 4 n-3$ & $0 \cdot 11 \pm 0 \cdot 025$ & $0 \cdot 10 \pm 0 \cdot 031$ & NS \\
\hline $20: 5 n-3$ & $0 \cdot 18 \pm 0 \cdot 052$ & $0 \cdot 20 \pm 0 \cdot 056$ & NS \\
\hline $22: 6 n-3$ & $2 \cdot 03 \pm 0 \cdot 115$ & $1 \cdot 03 \pm 0 \cdot 091$ & $<0 \cdot 001$ \\
\hline 18:1 trans & $0 \cdot 32 \pm 0 \cdot 070$ & $0 \cdot 43 \pm 0 \cdot 103$ & NS \\
\hline 18:2 trans, trans & $0 \cdot 08 \pm 0 \cdot 024$ & $0 \cdot 01 \pm 0 \cdot 010$ & $0 \cdot 029$ \\
\hline SFA & $34 \cdot 13 \pm 1 \cdot 235$ & $34 \cdot 70 \pm 1 \cdot 091$ & NS \\
\hline MUFA & $18 \cdot 42 \pm 1 \cdot 130$ & $25 \cdot 48 \pm 1 \cdot 44$ & $0 \cdot 001$ \\
\hline N-6 PUFA & $43 \cdot 83 \pm 1 \cdot 883$ & $36 \cdot 64 \pm 1 \cdot 450$ & $0 \cdot 007$ \\
\hline N-3 PUFA & $3 \cdot 00 \pm 0 \cdot 167$ & $2 \cdot 32 \pm 0 \cdot 250$ & $0 \cdot 037$ \\
\hline N-6/n-3 PUFA & $14 \cdot 9 \pm 0 \cdot 89$ & $17 \cdot 8 \pm 2 \cdot 21$ & NS \\
\hline TRANS FA & $0 \cdot 62 \pm 0 \cdot 078$ & $0 \cdot 86 \pm 0 \cdot 147$ & NS \\
\hline
\end{tabular}

Data are presented as mean \pm S.E.M. Comparisons were performed by the Student's $t$-test. SFA, saturated fatty acids; MUFA, monounsaturated fatty acids; PUFA, polyunsaturated fatty acids. Data in bold represents statistical significance, $P<0.05$

DHEA-treated rats (Table 5), where we found again a lower $n-6 / n-3$ PUFA ratio, in this case caused mainly by significantly higher $n-3$ PUFA levels.

DHEA treatment also altered the estimates of desaturase activity calculated by their product/substrate ratios (Fig. 1). The ratios calculated with serum FAs are commonly used as estimates of hepatic desaturase activities (Sjögren et al. 2008). In serum from DHEA-treated rats, the ratio 16:1 n-7/16:0 was reduced while 18:1 n-9/18:0 was increased (both are markers of stearoyl-CoA desaturase - SCD- activity); by contrary, in the s.c. and interscapular brown ATs both indices were lower (Fig. 1A and B). By contrast, the markers of delta6-desaturase activity in n-6 PUFA were increased, with significantly higher 18:3/18:2 n-6 and 20:4/18:2 n-6 ratios (Fig. 1C and D).

When FA data from AT samples were analyzed by means of the two-way ANOVA test, the interactions DHEA $\times$ tissue were non-significant for several FAs, which means that in these cases all fat depots responded to DHEA treatment in a similar way. However, other changes were indeed tissuespecific. For instance, variations in total n-3 PUFA were specific for s.c. and brown AT $\left(P_{\text {interaction }}=0 \cdot 047\right)$; similarly, reductions in the proportions of $16: 1 n-7$ and in the $n-6 / n-3$ PUFA ratio were more pronounced in these two depots $\left(P_{\mathrm{i}}=0.001\right.$ for both variables). Other FAs that varied in a 
Table 2 Selected fatty acids in periovarian adipose tissue from experimental groups

\begin{tabular}{|c|c|c|c|}
\hline \multirow[b]{2}{*}{ Fatty acids (\%) } & Control $(n=10)$ & DHEA $(n=11)$ & \multirow[t]{2}{*}{$P$} \\
\hline & & & \\
\hline 12:0 & $0 \cdot 32 \pm 0 \cdot 090$ & $0 \cdot 30 \pm 0 \cdot 034$ & NS \\
\hline 14:0 & $0 \cdot 92 \pm 0 \cdot 087$ & $0.93 \pm 0.028$ & NS \\
\hline $16: 0$ & $30 \cdot 35 \pm 0 \cdot 583$ & $30 \cdot 97 \pm 0 \cdot 602$ & NS \\
\hline 18:0 & $2 \cdot 48 \pm 0 \cdot 103$ & $2 \cdot 68 \pm 0 \cdot 113$ & NS \\
\hline $16: 1 n-9$ & $0 \cdot 62 \pm 0 \cdot 047$ & $0 \cdot 83 \pm 0 \cdot 044$ & $0 \cdot 004$ \\
\hline $16: 1 n-7$ & $2 \cdot 67 \pm 0.232$ & $2 \cdot 41 \pm 0 \cdot 245$ & NS \\
\hline $18: 1 n-9$ & $48 \cdot 81 \pm 0 \cdot 400$ & $47 \cdot 60 \pm 1 \cdot 523$ & NS \\
\hline $18: 1 n-7$ & $3 \cdot 01 \pm 0 \cdot 170$ & $4 \cdot 44 \pm 1 \cdot 525$ & NS \\
\hline $18: 2 n-6$ & $8 \cdot 46 \pm 0 \cdot 205$ & $7 \cdot 29 \pm 0 \cdot 094$ & $<0.001$ \\
\hline $18: 3 n-6$ & $0 \cdot 05 \pm 0 \cdot 004$ & $0 \cdot 11 \pm 0 \cdot 009$ & $<0.001$ \\
\hline $20: 3 n-6$ & $0.03 \pm 0.006$ & $0 \cdot 05 \pm 0 \cdot 008$ & $0 \cdot 055$ \\
\hline $20: 4 n-6$ & $0 \cdot 26 \pm 0 \cdot 023$ & $0 \cdot 45 \pm 0 \cdot 023$ & $<0 \cdot 001$ \\
\hline $18: 3 n-3$ & $0 \cdot 20 \pm 0 \cdot 017$ & $0 \cdot 19 \pm 0 \cdot 020$ & NS \\
\hline $18: 4 n-3$ & $0 \cdot 05 \pm 0 \cdot 008$ & $0 \cdot 10 \pm 0 \cdot 007$ & $<0 \cdot 001$ \\
\hline $20: 5 n-3$ & $0 \cdot 01 \pm 0 \cdot 006$ & $0 \cdot 03 \pm 0 \cdot 013$ & NS \\
\hline $22: 6 n-3$ & $0 \cdot 04 \pm 0 \cdot 006$ & $0 \cdot 04 \pm 0 \cdot 002$ & NS \\
\hline 18:1 trans & $0 \cdot 18 \pm 0 \cdot 044$ & $0 \cdot 12 \pm 0.011$ & NS \\
\hline $18: 2$ cis, trans & $0 \cdot 16 \pm 0 \cdot 010$ & $0 \cdot 27 \pm 0 \cdot 014$ & $<0 \cdot 001$ \\
\hline SFA & $34 \cdot 91 \pm 0.632$ & $35 \cdot 52 \pm 0 \cdot 543$ & NS \\
\hline MUFA & $55 \cdot 27 \pm 0 \cdot 571$ & $55 \cdot 44 \pm 0 \cdot 531$ & NS \\
\hline N-6 PUFA & $8 \cdot 99 \pm 0 \cdot 189$ & $8 \cdot 07 \pm 0 \cdot 083$ & $0 \cdot 001$ \\
\hline N-3 PUFA & $0 \cdot 33 \pm 0 \cdot 034$ & $0.41 \pm 0.033$ & NS \\
\hline$N-6 / n-3$ PUFA & $30 \cdot 0 \pm 3 \cdot 62$ & $21 \cdot 4 \pm 2 \cdot 58$ & $0 \cdot 063$ \\
\hline TRANS FA & $0 \cdot 50 \pm 0 \cdot 057$ & $0 \cdot 55 \pm 0 \cdot 019$ & NS \\
\hline
\end{tabular}

Data are presented as mean \pm S.E.M. Comparisons were performed by the Student's $t$-test. SFA, saturated fatty acids; MUFA, monounsaturated fatty acids; PUFA, polyunsaturated fatty acids. Data in bold represents statistical significance, $P<0.05$

tissue-specific manner were 14:0 $\left(P_{\mathrm{i}}=0 \cdot 048\right), 20: 3 n-6$ $\left(P_{\mathrm{i}}<0 \cdot 001\right), \quad 18: 4 \quad n-3 \quad\left(P_{\mathrm{i}}=0 \cdot 001\right), \quad 18: 2 \quad$ cis, trans $\left(P_{\mathrm{i}}<0 \cdot 001\right)$, and 18:2 trans, trans $\left(P_{\mathrm{i}}<0 \cdot 001\right)$.

\section{Discussion}

We had previously reported that DHEA administration to our rats led to significant reductions in food intake, body weight, total body fat content, the weight of different adipose depots, and adipocyte size (de Heredia et al. 2007). In addition, we found that DHEA-treated rats had significantly lower serum insulin concentrations and a tendency to lower HOMA-IR index (Sánchez et al. 2008). The present work has revealed that DHEA treatment also induced significant changes in FA profile in serum and AT from those rats, and that these changes varied according to the tissue studied. We found elevated n-9 MUFA in serum and s.c. AT, reduced n-6 PUFA in serum and white adipose depots, and increased n-3 PUFA (18:4 $n-3$ in all adipose regions, 20:5 n-3 in s.c. tissue and total n-3 PUFA in interscapular brown AT). Besides, DHEA treatment altered the surrogate estimates of desaturase activities, again in a tissue-specific manner.

This is to our knowledge, the first work that demonstrates a significant effect of DHEA on AT fatty acid composition.
There is a previous work that reported no changes in rat AT fatty acids after 7 days of DHEA administration (Abadie et al. 2001). However, due to the lower lipid turn-over rate of this tissue, a 7-day period may not be long enough to appreciate variations in FA profile in AT. By contrast, our experiment spanned a 13-week period that allowed us to observe a significant effect of DHEA on AT composition. Similarly to us, other authors have reported differences in FAs in muscle (Abadie et al. 2001), liver (Imai et al. 2001), and 3T3-L1 adipocytes (Gómez et al. 2002) due to DHEA administration.

In our study, changes in serum 16:0 (increased) and 18:0 (decreased) observed in the DHEA group were not reflected in AT; on the contrary, individual SFA did not varied in the visceral depots, while 18:0 was higher in s.c. and brown ATs of DHEA-treated rats. The increment in serum 16:0 after DHEA administration is somehow surprising, since this FA induces peripheral insulin resistance (Chávez \& Summers 2003, Powell et al. 2004), but we observed lower insulin concentrations in DHEA-treated rats (Sánchez et al. 2008). However, it seems that impairment of peripheral insulin sensitivity by $16: 0$ is produced by conversion of this FA into ceramides (Chávez \& Summers 2003, Powell et al. 2004), and DHEA could be counteracting this process somehow.

Other FAs associated with insulin resistance are trans FAs (Saravanan et al. 2005). In the present work, total trans FAs

Table 3 Selected fatty acids in mesenteric adipose tissue from experimental groups

\begin{tabular}{|c|c|c|c|}
\hline \multirow[b]{2}{*}{ Fatty acids (\%) } & Control $(n=10)$ & DHEA $(n=11)$ & \multirow[t]{2}{*}{$\boldsymbol{P}$} \\
\hline & & & \\
\hline $12: 0$ & $0 \cdot 09 \pm 0 \cdot 020$ & $0 \cdot 11 \pm 0 \cdot 051$ & NS \\
\hline $14: 0$ & $0.76 \pm 0.039$ & $0.87 \pm 0.055$ & NS \\
\hline $16: 0$ & $30 \cdot 99 \pm 0 \cdot 384$ & $31 \cdot 57 \pm 0.495$ & NS \\
\hline 18:0 & $3 \cdot 17 \pm 0 \cdot 210$ & $3 \cdot 41 \pm 0 \cdot 128$ & NS \\
\hline $16: 1 n-9$ & $0 \cdot 52 \pm 0 \cdot 029$ & $0 \cdot 78 \pm 0 \cdot 041$ & $<0 \cdot 001$ \\
\hline $16: 1 n-7$ & $2 \cdot 39 \pm 0 \cdot 222$ & $2 \cdot 00 \pm 0 \cdot 240$ & NS \\
\hline $18: 1 n-9$ & $47 \cdot 72 \pm 0 \cdot 598$ & $48 \cdot 95 \pm 0 \cdot 505$ & NS \\
\hline $18: 1 n-7$ & $2 \cdot 59 \pm 0 \cdot 082$ & $1 \cdot 89 \pm 0 \cdot 076$ & $<0 \cdot 001$ \\
\hline $18: 2 n-6$ & $8 \cdot 43 \pm 0 \cdot 161$ & $7 \cdot 22 \pm 0 \cdot 107$ & $<0.001$ \\
\hline $18: 3 n-6$ & $0 \cdot 05 \pm 0 \cdot 008$ & $0 \cdot 12 \pm 0 \cdot 005$ & $<0 \cdot 001$ \\
\hline $20: 3 n-6$ & $0 \cdot 03 \pm 0 \cdot 004$ & $0 \cdot 07 \pm 0 \cdot 004$ & $<0 \cdot 001$ \\
\hline $20: 4 n-6$ & $0 \cdot 27 \pm 0 \cdot 043$ & $0 \cdot 52 \pm 0.035$ & $<0 \cdot 001$ \\
\hline $18: 3 n-3$ & $0 \cdot 22 \pm 0 \cdot 016$ & $0 \cdot 21 \pm 0 \cdot 010$ & NS \\
\hline $18: 4 n-3$ & $0 \cdot 09 \pm 0 \cdot 012$ & $0 \cdot 12 \pm 0 \cdot 007$ & $0 \cdot 012$ \\
\hline $20: 5 n-3$ & $0.02 \pm 0.006$ & $0 \cdot 04 \pm 0 \cdot 005$ & NS \\
\hline $22: 6 n-3$ & $0 \cdot 12 \pm 0 \cdot 082$ & $0 \cdot 04 \pm 0 \cdot 006$ & NS \\
\hline 18:1 trans & $0 \cdot 28 \pm 0.062$ & $0 \cdot 19 \pm 0 \cdot 031$ & NS \\
\hline $18: 2$ cis, trans & $0 \cdot 20 \pm 0 \cdot 006$ & $0 \cdot 31 \pm 0 \cdot 007$ & $<0.001$ \\
\hline SFA & $36 \cdot 26 \pm 0 \cdot 787$ & $36 \cdot 84 \pm 0 \cdot 516$ & NS \\
\hline MUFA & $53 \cdot 50 \pm 0 \cdot 757$ & $53 \cdot 81 \pm 0 \cdot 513$ & NS \\
\hline N-6 PUFA & $8 \cdot 98 \pm 0 \cdot 179$ & $8 \cdot 12 \pm 0 \cdot 476$ & $0 \cdot 001$ \\
\hline N-3 PUFA & $0.53 \pm 0.073$ & $0 \cdot 48 \pm 0 \cdot 023$ & NS \\
\hline$N-6 / n-3$ PUFA & $18 \cdot 7 \pm 1 \cdot 58$ & $17 \cdot 2 \pm 0 \cdot 83$ & NS \\
\hline TRANS FA & $0 \cdot 72 \pm 0 \cdot 060$ & $0.75 \pm 0.034$ & NS \\
\hline
\end{tabular}

Data are presented as mean \pm S.E.M. Comparisons were performed by the Student's $t$-test. SFA, saturated fatty acids; MUFA, monounsaturated fatty acids; PUFA, polyunsaturated fatty acids. Data in bold represents statistical significance, $P<0.05$ 
Table 4 Selected fatty acids in subcutaneous adipose tissue from experimental groups

\begin{tabular}{|c|c|c|c|}
\hline \multirow[b]{2}{*}{ Fatty acids (\%) } & Control $(n=10)$ & DHEA $(n=11)$ & \multirow[t]{2}{*}{$\boldsymbol{P}$} \\
\hline & & & \\
\hline $12: 0$ & $0 \cdot 34 \pm 0 \cdot 044$ & $0 \cdot 22 \pm 0 \cdot 029$ & $0 \cdot 039$ \\
\hline 14:0 & $1 \cdot 04 \pm 0 \cdot 052$ & $0 \cdot 87 \pm 0 \cdot 030$ & $0 \cdot 010$ \\
\hline 16:0 & $30 \cdot 07 \pm 0 \cdot 604$ & $29 \cdot 72 \pm 1 \cdot 167$ & NS \\
\hline 18:0 & $2 \cdot 60 \pm 0 \cdot 272$ & $3 \cdot 45 \pm 0 \cdot 132$ & $0 \cdot 009$ \\
\hline $16: 1 n-9$ & $0 \cdot 57 \pm 0 \cdot 044$ & $0 \cdot 73 \pm 0 \cdot 045$ & $0 \cdot 020$ \\
\hline $16: 1 n-7$ & $3 \cdot 54 \pm 0 \cdot 524$ & $1 \cdot 33 \pm 0 \cdot 107$ & $0 \cdot 002$ \\
\hline $18: 1 n-9$ & $47 \cdot 53 \pm 0 \cdot 601$ & $50 \cdot 08 \pm 1 \cdot 033$ & $0 \cdot 052$ \\
\hline $18: 1 n-7$ & $2 \cdot 94 \pm 0 \cdot 207$ & $2 \cdot 37 \pm 0 \cdot 133$ & $0 \cdot 029$ \\
\hline $18: 2 n-6$ & $8 \cdot 71 \pm 0 \cdot 082$ & $7 \cdot 75 \pm 0 \cdot 136$ & $<0.001$ \\
\hline $18: 3 n-6$ & $0 \cdot 06 \pm 0.005$ & $0 \cdot 09 \pm 0.008$ & $0 \cdot 001$ \\
\hline $20: 3 n-6$ & $0 \cdot 04 \pm 0 \cdot 005$ & $0 \cdot 08 \pm 0.006$ & $<0.001$ \\
\hline $20: 4 n-6$ & $0 \cdot 50 \pm 0.042$ & $0 \cdot 73 \pm 0.031$ & $<0.001$ \\
\hline $18: 3 n-3$ & $0 \cdot 17 \pm 0 \cdot 047$ & $0 \cdot 19 \pm 0 \cdot 030$ & NS \\
\hline $18: 4 n-3$ & $0 \cdot 05 \pm 0 \cdot 007$ & $0 \cdot 12 \pm 0 \cdot 007$ & $<0.001$ \\
\hline $20: 5 n-3$ & $0 \cdot 03 \pm 0 \cdot 004$ & $0 \cdot 05 \pm 0.009$ & $0 \cdot 026$ \\
\hline $22: 6 n-3$ & $0 \cdot 05 \pm 0.008$ & $0 \cdot 05 \pm 0 \cdot 004$ & NS \\
\hline $18: 1$ trans & $0 \cdot 18 \pm 0 \cdot 021$ & $0 \cdot 22 \pm 0 \cdot 030$ & NS \\
\hline 18:2 cis, trans & $0 \cdot 17 \pm 0 \cdot 009$ & $0 \cdot 26 \pm 0 \cdot 012$ & $<0.001$ \\
\hline SFA & $35 \cdot 20 \pm 0 \cdot 960$ & $35 \cdot 53 \pm 1 \cdot 247$ & NS \\
\hline MUFA & $55 \cdot 46 \pm 1 \cdot 063$ & $55 \cdot 59 \pm 1 \cdot 155$ & NS \\
\hline N-9 MUFA & $48 \cdot 42 \pm 0 \cdot 610$ & $51 \cdot 18 \pm 1 \cdot 073$ & $0 \cdot 043$ \\
\hline N-6 PUFA & $9 \cdot 56 \pm 0 \cdot 097$ & $8 \cdot 93 \pm 0 \cdot 139$ & $0 \cdot 002$ \\
\hline N-3 PUFA & $0 \cdot 35 \pm 0 \cdot 047$ & $0 \cdot 48 \pm 0 \cdot 045$ & $0 \cdot 061$ \\
\hline N-6/n-3 PUFA & $29 \cdot 9 \pm 2 \cdot 28$ & $19 \cdot 9 \pm 1 \cdot 52$ & $0 \cdot 001$ \\
\hline TRANS FA & $0 \cdot 54 \pm 0 \cdot 033$ & $0 \cdot 68 \pm 0 \cdot 040$ & $0 \cdot 011$ \\
\hline
\end{tabular}

Data are presented as mean \pm S.E.M. Comparisons were performed by the Student's $t$-test. SFA, saturated fatty acids; MUFA, monounsaturated fatty acids; PUFA, polyunsaturated fatty acids. Data in bold represents statistical significance, $P<0.05$

practically did not change because of DHEA in the different fat depots. We found lower proportions of 18:2 trans, trans in serum and higher percentages of 18:2 cis, trans and 18:2 trans, cis in AT of DHEA-treated rats, but these are minority trans isomers and even their quantification is very difficult. The main trans isomer in diet and tissues is 18:1 trans that were practically not modified by the hormonal treatment.

More remarkable were the changes in $n-9$ MUFA. These FAs, of which oleic (18:1 n-9) is the most representative, were significantly higher in the serum and s.c. AT from the DHEA group than from the control one. Quite the opposite, palmitoleic acid (16:1 n-7) was reduced in s.c. and brown AT (and in serum, with marginal significance). These results are in agreement with those obtained by Imai et al. (2001), who observed that DHEA stimulates oleate synthesis, resulting in increased 18:1 n-9 contents in liver, and with Gómez et al. (2002), who also reported reduced 16:1 n-7 and elevated 18:1 n-9 in 3T3-L1 adipocytes treated with DHEA.

Different authors have reported that oleic acid is negatively associated with features of the metabolic syndrome (Garaulet et al. 2001, Carluccio et al. 2007), and positively with enhanced peripheral glucose uptake (Vessby et al. 1994, Dimopoulos et al. 2006). Regarding palmitoleic acid, it also has been shown to increase glucose uptake in vitro (Dimopoulos et al. 2006), whereas other authors have proposed it as a marker for metabolic risk (Gil-Campos et al. 2008, Paillard et al. 2008). Although it remains to be determined, whether increments in palmitoleic acid indicate causal or compensatory events for insulin resistance, higher levels of this FA are related to metabolic alterations. In light of these data, it could be suggested that the insulin-lowering effect of DHEA that we observed may be related to the higher oleic acid and the reduced palmitoleic acid proportions in the tissues of DHEA-treated rats.

PUFA were also affected by DHEA treatment in our study. In serum, the DHEA group showed a significant reduction of linoleic (18:2 n-6) and arachidonic (20:4 n-6) acids. In AT, linoleic acid was also lower while arachidonic acid was higher, in agreement with observations in rat liver (Imai et al. 2001). Some authors have reported negative associations between n-6 PUFA and insulin sensitivity (Vessby et al. 1994, Aldámiz-Echevarría et al. 2007), while others found positive ones (Nugent et al. 2001, Dimopoulos et al. 2006). The relation between n-6 PUFA and insulin sensitivity could depend on the localization of the FAs, so that high levels in serum would be related to insulin resistance, while in AT or skeletal muscle they would help to improve sensitivity. If this was the case, the reduction in serum n-6 PUFA in DHEAtreated rats observed in our work might be related to the lower insulin concentrations found in these animals. By

Table 5 Selected fatty acids in interscapular brown adipose tissue from experimental groups

\begin{tabular}{|c|c|c|c|}
\hline \multirow[b]{2}{*}{ Fatty acids (\%) } & Control $(n=10)$ & DHEA $(n=11)$ & \multirow[t]{2}{*}{$\boldsymbol{P}$} \\
\hline & & & \\
\hline $12: 0$ & $0 \cdot 04 \pm 0 \cdot 007$ & $0 \cdot 03 \pm 0 \cdot 017$ & NS \\
\hline 14:0 & $0.95 \pm 0.048$ & $0 \cdot 85 \pm 0 \cdot 048$ & NS \\
\hline $16: 0$ & $25 \cdot 28 \pm 0 \cdot 254$ & $24 \cdot 82 \pm 0 \cdot 379$ & NS \\
\hline 18:0 & $5 \cdot 59 \pm 0 \cdot 439$ & $6 \cdot 66 \pm 0 \cdot 234$ & $0 \cdot 050$ \\
\hline $16: 1 n-9$ & $0 \cdot 53 \pm 0.028$ & $0 \cdot 63 \pm 0.024$ & $0 \cdot 019$ \\
\hline $16: 1 n-7$ & $1 \cdot 53 \pm 0 \cdot 170$ & $\mathbf{0} \cdot \mathbf{8 0} \pm \mathbf{0 \cdot 0 7 7}$ & $0 \cdot 002$ \\
\hline $18: 1 n-9$ & $46 \cdot 81 \pm 0 \cdot 410$ & $47 \cdot 45 \pm 0 \cdot 234$ & NS \\
\hline $18: 1 n-7$ & $7 \cdot 30 \pm 0 \cdot 274$ & $6 \cdot 84 \pm 0 \cdot 532$ & NS \\
\hline $18: 2 n-6$ & $8 \cdot 88 \pm 0 \cdot 134$ & $7 \cdot 67 \pm 0 \cdot 130$ & $<0 \cdot 001$ \\
\hline $18: 3 n-6$ & $0 \cdot 07 \pm 0.003$ & $0 \cdot 12 \pm 0 \cdot 007$ & $<0 \cdot 001$ \\
\hline $20: 3 n-6$ & $0 \cdot 10 \pm 0 \cdot 008$ & $0 \cdot 20 \pm 0 \cdot 014$ & $<0.001$ \\
\hline $20: 4 n-6$ & $1 \cdot 19 \pm 0 \cdot 121$ & $1 \cdot 55 \pm 0 \cdot 171$ & NS \\
\hline $18: 3 n-3$ & $0 \cdot 10 \pm 0 \cdot 038$ & $0 \cdot 16 \pm 0 \cdot 049$ & NS \\
\hline $18: 4 n-3$ & $0 \cdot 04 \pm 0.005$ & $0 \cdot 14 \pm 0 \cdot 011$ & $<0.001$ \\
\hline $20: 5 n-3$ & $0 \cdot 03 \pm 0.003$ & $0 \cdot 06 \pm 0 \cdot 010$ & $0 \cdot 022$ \\
\hline $22: 6 n-3$ & $0 \cdot 06 \pm 0 \cdot 006$ & $0 \cdot 08 \pm 0 \cdot 008$ & NS \\
\hline 18:1 trans & $0 \cdot 06 \pm 0 \cdot 007$ & $0 \cdot 07 \pm 0 \cdot 012$ & NS \\
\hline $18: 2$ cis, trans & $0 \cdot 09 \pm 0 \cdot 005$ & $0 \cdot 10 \pm 0 \cdot 004$ & $0 \cdot 035$ \\
\hline $18: 2$ trans, cis & $0 \cdot 07 \pm 0 \cdot 005$ & $\mathbf{0} \cdot \mathbf{1 5} \pm \mathbf{0 \cdot 0 0 7}$ & $<0.001$ \\
\hline SFA & $32 \cdot 41 \pm 0 \cdot 282$ & $33 \cdot 06 \pm 0.354$ & NS \\
\hline MUFA & $56 \cdot 55 \pm 0 \cdot 460$ & $56 \cdot 21 \pm 0 \cdot 408$ & NS \\
\hline N-6 PUFA & $10 \cdot 57 \pm 0 \cdot 253$ & $9 \cdot 95 \pm 0 \cdot 228$ & NS \\
\hline N-3 PUFA & $0 \cdot 25 \pm 0 \cdot 046$ & $0 \cdot 47 \pm 0 \cdot 057$ & $0 \cdot 009$ \\
\hline$N-6 / n-3$ PUFA & $54 \cdot 4 \pm 8 \cdot 0$ & $23 \cdot 9 \pm 2 \cdot 54$ & $0 \cdot 004$ \\
\hline TRANS FA & $0 \cdot 22 \pm 0 \cdot 009$ & $0 \cdot 32 \pm 0 \cdot 015$ & $<0 \cdot 001$ \\
\hline
\end{tabular}

Data are presented as mean \pm S.E.M. Comparisons were performed by the Student's t-test. SFA, saturated fatty acids; MUFA, monounsaturated fatty acids; PUFA, polyunsaturated fatty acids. Data in bold represents statistical significance, $P<0.05$ 
$16: 1 / 16: 0$

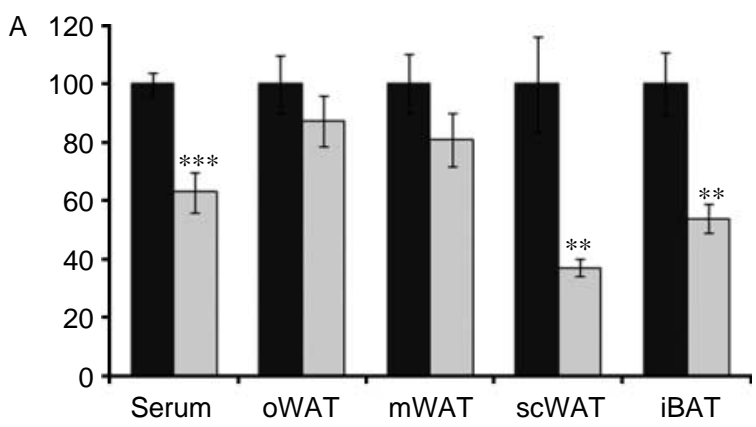

18:1/18:0

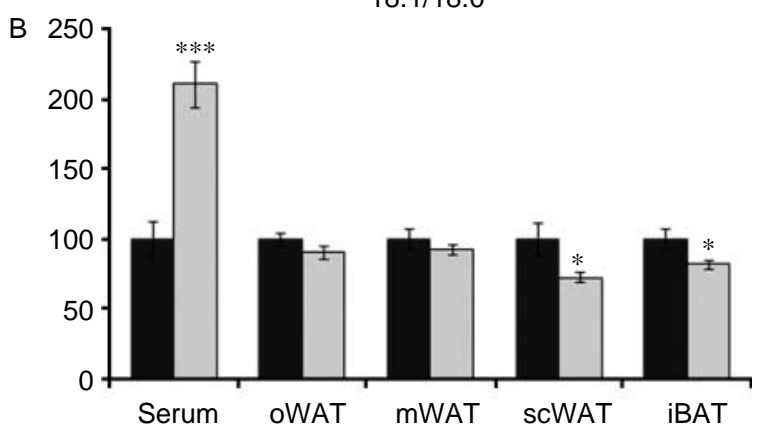

18:3/18:2 $n-6$

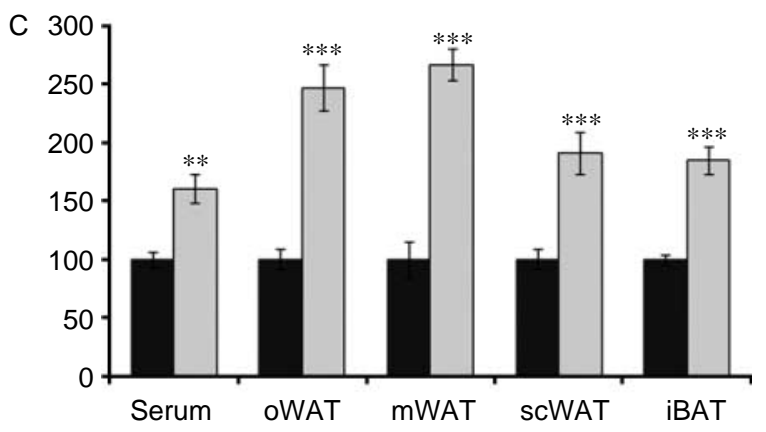

20:4/18:2

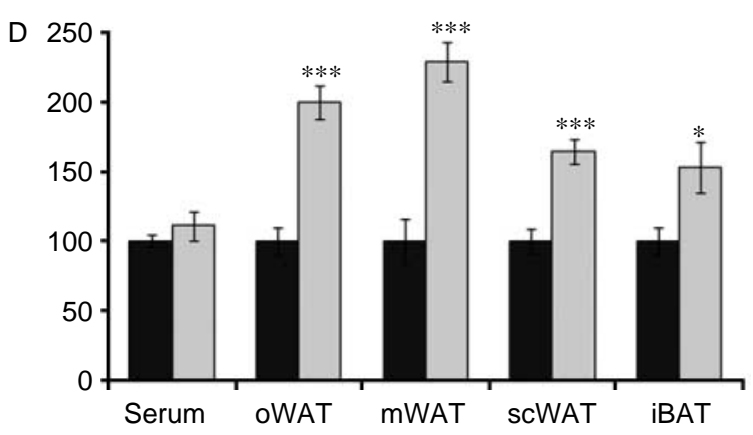

contrast to $n-6 \mathrm{FAs}$, our results show increased proportions of n-3 PUFA in brown AT in rats receiving DHEA. It has been proposed that $n-3$ PUFA in brown AT are related to UCP-1 levels (Takahashi \& Ide 2000), and DHEA has been shown to increase brown fat UCP-1 levels (Ryu et al. 2003); therefore, we hypothesize that DHEA treatment could enhance brown fat thermogenesis, at least in part, through increments in $n-3$ PUFA contents.

Of note, the changes in PUFA proportions led to significant reductions in $n-6 / n-3$ PUFA ratios in s.c. and brown ATs--and the same trend was followed by the other adipose regions analyzed- of DHEA-treated rats. It has been proposed that high $n-6 / n-3$ PUFA ratios are associated with greater body fat accumulation, cardiovascular risk, and inflammatory processes (Ghafoorunissa et al. 2005, Ailhaud et al. 2006, Riediger et al. 2008); therefore, the lower $n-6 / n-3$ ratios observed in the present work could be a part of the protective actions attributed to DHEA.

It is interesting to highlight that the effects of DHEA on AT seem to be depot-specific, since the changes observed varied among the different tissues analyzed. It appeared that the s.c. white AT and the interscapular brown AT were more affected by the treatment, while the changes in the visceral depots were less pronounced. These results could be related, among other possible causes, to the fact that this experiment was conducted in female rats, since previous work performed in humans showed a gender-specific action of DHEA on AT, its effects being more evident in visceral fat among men and in s.c. fat among women (Hernández-Morante et al. 2008). Further studies should be carried out in order to confirm this hypothesis.

Finally, in our experiment, DHEA administration also modified significantly the estimates of desaturase activities. In serum of DHEA-treated rats, the marker of SCD activity on C18 (ratio 18:1/18:0) was increased, while SCD on C16 (ratio 16:1/16:0) was reduced. These indices are commonly used as estimates of hepatic desaturase activity, based on the fact that in the fasting state most serum FAs are derived from the liver (Sjögren et al. 2008). Some authors have suggested that higher SCD activity leading to increased synthesis of palmitoleic acid might be involved in metabolic alterations associated with obesity (Gil-Campos et al. 2008, Paillard et al. 2008). Therefore, these inverse changes observed in serum SCD markers that imply decreased palmitoleic and increased oleic synthesis could partly mediate the beneficial effects of DHEA. In AT, in contrast,

Figure 1 Desaturase activities estimated by product/substrate ratios of different fatty acids. Values in the DHEA group (light bars) are expressed as percentages of average values from the control group (dark bars). Serum ratios reflect indirectly hepatic desaturase activities. (A) Estimates of delta-9 desaturase activity on C16; (B) Estimates of delta-9 desaturase activity on C18; (C and D) Estimates of delta- 6 desaturase activity. oWAT, periovarian adipose tissue; mWAT, mesenteric adipose tissue; scWAT, s.c. adipose tissue; iBAT, interscapular adipose tissue. Significant differences at $* P<0.05 ; * * P<0.01 ; * * * P<0.001$ 
the two markers of SCD activity were lower in the DHEA group than in the control one, the difference being significant in the s.c. and brown depots. It is worth highlighting that our results show opposite trends in serum and AT 18:1/18:0 in response to DHEA treatment. These changes are in agreement with the findings by Imai et al. and Gómez et al. The former observed that DHEA induces SCD in liver to increase 18:1 synthesis (Imai et al. 2001), which would explain the higher 18:1/18:0 ratio found in serum in our work, while the latter found that DHEA inhibits SCD expression in adipocytes in vitro (Gómez et al. 2002), leading to the lower 18:1/18:0 ratio in AT, mainly in the s.c. and brown depots. In addition, we found a general increment in the markers of delta-6-desaturase activity in the DHEA group. To our knowledge, no previous data are available on the effects of DHEA on delta-6-desaturase activity. Considering that SCD activity in AT has been associated with insulin resistance (Dobrzyn \& Ntambi 2005, Sjögren et al. 2008), and that delta-6-desaturase has been reported to be involved in insulin-stimulated glucose uptake (Das 2005), this DHEA-related reduction in SCD markers in AT together with the increased delta-6-desaturase estimates observed in our work could reflect another mechanism by which DHEA improves insulin sensitivity.

It must be kept in mind that other major tissues, such as liver and muscle, play an important role in insulin resistance and they also seem to be targets for DHEA; therefore, they should be taken into account when dealing with systemic insulin sensitivity. Nevertheless, the contribution of AT should not be underestimated, considering that it is one of the main sites for insulin action and the principal source for circulating FAs in the body.

In summary, we have demonstrated for the first time that pharmacological administration of DHEA modifies significantly the FA profiles in serum and different AT depots in rats, and that changes vary according to the tissue studied. The hormone affected mainly $n-9$ MUFA, palmitoleic acid, $n-6$ PUFA, and n-3 PUFA, and also the markers of desaturase activities. Although the relationships among DHEA, FAs and insulin sensitivity are still poorly understood, we hypothesize that changes in FAs due to DHEA treatment may be related to DHEA's insulin-lowering effect, and speculate that the lower insulin levels might be accompanied by improved insulin sensitivity.

\section{Declaration of interest}

The authors declare that there is no conflict of interest that could be perceived as prejudicing the impartiality of the research reported.

\section{Funding}

This work was supported by the Seneca Foundation from the Government of Murcia (project 02934/PI/05 to M G).

\section{References}

Abadie JM, Malcolm GT, Porter JR \& Svec F 2001 Dehydroepiandrosterone alters Zucker rat soleus and cardiac muscle lipid profiles. Experimental Biology and Medicine 226 78278-78279.

Ailhaud G, Massiera F, Weill P, Legrand P, Alessandri JM \& Guesnet P 2006 Temporal changes in dietary fats: role of $n-6$ polyunsaturated fatty acids in excessive adipose tissue development and relationship to obesity. Progress in Lipid Research 45 203-236.

Aldámiz-Echevarría L, Prieto JA, Andrade F, Elorz J, Sanjurjo P \& Rodríguez Soriano J 2007 Arachidonic acid content in adipose tissue is associated with insulin resistance in healthy children. Journal of Pediatric Gastroenterology and Nutrition 44 77-83.

Arlt W 2004 Dehydroepiandrosterone and aging. Best Practice and Research. Clinical Endocrinology and Metabolism 18 363-380.

Carluccio MA, Massaro M, Scoditti E \& De Caterina R 2007 Vasculoprotective potential of olive oil components. Molecular Nutrition $\mathcal{E}$ Food Research 51 1225-1234.

Chávez JA \& Summers SA 2003 Characterizing the effects of saturated fatty acids on insulin signalling and ceramide and diacylglycerol accumulation in 3T3-L1 adipocytes and C2C12 myotubes. Archives of Biochemistry and Biophysics 419 101-109.

Das UN 2005 A defect in the activity of Delta6 and Delta5 desaturases may be a factor predisposing to the development of insulin resistance syndrome. Prostaglandins, Leukotrienes and Essential Fatty Acids 72 343-350.

Depreter M, Vandesompele J, Espeel M, Speleman F \& Roels F 2002 Modulation of the peroxisomal gene expression pattern by dehydroepiandrosterone and vitamin D: therapeutic implications. Journal of Endocrinology 175 779-792.

Dimopoulos N, Watson M, Sakamoto K \& Hundal HS 2006 Differential effects of palmitate and palmitoleate on insulin action and glucose utilization in rat L6 skeletal muscle cells. Biochemical Journal 399 473-481.

Dobrzyn A \& Ntambi JM 2005 The role of stearoyl-CoA desaturase in the control of metabolism. Prostaglandins, Leukotrienes and Essential Fatty Acids 73 35-41.

Drevon CA 2005 Fatty acids and expression of adipokines. Biochimica et Biophysica Acta 1740 287-292.

Ebeling P \& Koivisto VA 1994 Physiological importance of dehydroepiandrosterone. Lancet 343 1479-1481.

Folch J, Lees M \& Stanley GH 1957 A simple method for the isolation and purification of total lipids from animal tissues. Journal of Biological Chemistry 226 497-509.

Garaulet M, Pérez-Llamas F, Pérez-Ayala M, Martínez P, de Medina FS, Tebar FJ \& Zamora S 2001 Site-specific differences in the fatty acid composition of abdominal adipose tissue in an obese population from a Mediterranean area: relation with dietary fatty acids, plasma lipid profile, serum insulin, and central obesity. American Journal of Clinical Nutrition 74 585-591.

Ghafoorunissa, Ibrahim A \& Natarajan S 2005 Substituting dietary linoleic acid with alpha-linolenic acid improves insulin sensitivity in sucrose fed rats. Biochimica et Biophysica Acta 1733 67-75.

Gil-Campos M, Larqué E, Ramírez-Tortosa MC, Linde J, Villada I, Cañete R \& Gil A 2008 Changes in plasma fatty acid composition after intake of a standardised breakfast in prepubertal obese children. British Journal of Nutrition 99 909-917.

Gómez FE, Miyazaki M, Kim YC, Marwah P, Lardy HA, Ntmabi JM \& Fox BG 2002 Molecular differences caused by differentiation of 3T3-L1 preadipocytes in the presence of either dehydroepiandrosterone (DHEA) or 7-oxoDHEA. Biochemistry 41 5473-5482.

de Heredia FP, Cerezo D, Zamora S \& Garaulet M 2007 Effect of dehydroepiandrosterone on protein and fat digestibility, body protein and muscular composition in high-fat-diet-fed old rats. British Journal of Nutrition 97 464-470.

Hernández-Morante JJ, Pérez-de-Heredia F, Luján JA, Zamora S \& Garaulet M 2008 Role of DHEA-S on body fat distribution: gender- and depot-specific stimulation of adipose tissue lipolysis. Steroids 73 209-215. 
Imai K, Kudo N, Koyama M, Shirahata A \& Kawashima Y 2001 Effects of dehydroepiandrosterone on oleic acid formation in the liver of rats, mice and guinea pigs. Japanese Journal of Pharmacology 86 437-447.

Kajita K, Ishizuka T, Mune T, Miura A, Ishiwaza M, Kanoh Y, Kawai Y, Natsume Y \& Yasuda K 2003 Dehydroepiandrosterone down-regulates the expression of peroxisome proliferator-activated receptor- $\gamma$ in adipocytes. Endocrinology 144 253-259.

Kawai S, Yahata N, Nishida S, Nagai K \& Mizushima Y 1995 Dehydroepiandrosterone inhibits B16 mouse melanoma cell growth by induction of differentiation. Anticancer Research 15 427-431.

Kraegen EW, Cooney GJ, Ye J \& Thompson AL 2001 Triglycerides, fatty acids and insulin resistance - hyperinsulinemia. Experimental and Clinical Endocrinology and Diabetes 109 S516-S526.

Lea-Currie YR, Wen P \& McIntosh MK 1998 Dehydroepiandrosterone reduces proliferation and differentiation of 3T3-L1 preadipocytes. Biochemical and Biophysical Research Communications 248 497-504.

Liu D \& Dillon JS 2004 Dehydroepiandrosterone stimulates nitric oxide release in vascular endothelial cells: evidence for a cell surface receptor. Steroids $69279-289$.

Matthews DR, Hosker JP, Rudenski AS, Naylor BA, Treacher DF \& Turner RC 1985 Homeostasis model assessment: insulin resistance and beta-cell function from fasting plasma glucose and insulin concentrations in man. Diabetologia 28 412-419.

Nestler JE, Clore JN \& Blackard WG 1992 Dehydroepiandrosterone: the 'missing link' between hyperinsulinemia and atherosclerosis? FASEB Journal 6 3073-3075

Nugent C, Prins JB, Whitehead JP, Wentworth JM, Chatterjee VK \& O'Rahilly S 2001 Arachidonic acid stimulates glucose uptake in 3T3-L1 adipocytes by increasing GLUT1 and GLUT4 levels at the plasma membrane. Evidence for involvement of lipoxygenase metabolites and peroxisome proliferator-activated receptor gamma. Journal of Biological Chemistry 276 9149-9157.

Paillard F, Catheline D, Duff FL, Bouriel M, Deugnier Y, Pouchard M, Daubert JC \& Legrand P 2008 Plasma palmitoleic acid, a product of stearoyl-CoA desaturase activity, is an independent marker of triglyceridemia and abdominal obesity. Nutrition, Metabolism, and Cardiovascular Diseases 18 436-440.

Pérez de Heredia F, Larque E, Portillo MP, Canteras M, Zamora S \& Garaulet M 2008 Age-related changes in fatty acids from different adipose depots in rat and their association with adiposity and insulin. Nutrition 24 1013-1022.

Powell DJ, Turban S, Gray A, Hajduch E \& Hundal HS 2004 Intracellular ceramide synthesis and protein kinase $\mathrm{C} \zeta$ activation play an essential role in palmitate-induced insulin resistance in rat L6 skeletal muscle cells. Biochemical Journal 382 619-629.

Raclot T, Groscolas R, Langin D \& Ferré P 1997 Site-specific regulation of gene expression by $n-3$ polyunsaturated fatty acids in rat white adipose tissues. Journal of Lipid Research 38 1963-1972.

Ratko TA, Detrisac CJ, Mehta RG, Kelloff GJ \& Moon RC 1991 Inhibition of rat mammary gland chemical carcinogenesis by dietary dehydroepiandrosterone or a fluorinated analogue of dehydroepiandrosterone. Cancer Research 51 481-486.

Reeves PG, Nielsen FH \& Fahey GC Jr 1993 AIN-93 purified diets for laboratory rodents: final report of the American Institute of Nutrition Ad Hoc Writing Committee on the reformulation of the AIN-76A rodent diet. Journal of Nutrition 123 1939-1951.
Regelson W, Loria R \& Kalimi M 1994 Dehydroepiandrosterone (DHEA) the 'Mother Steroid.' I. Immunologic action. Annals of the New York Academy of Sciences 719 553-563.

Richards RJ, Porter JR \& Svec F 2000 Serum leptin, lipids, free fatty acids and fat-pads in long-term dehydroepiandrosterone-treated Zucker rats. Proceedings of the Society for Experimental Biology and Medicine 223 258-262.

Riediger ND, Othman R, Fitz E, Pierce GN, Suh M \& Moghadasian MH 2008 Low n-6:n-3 fatty acid ratio, with fish- or flaxseed oil, in a high fat diet improves plasma lipids and beneficially alters tissue fatty acid composition in mice. European Journal of Nutrition 47 153-160.

Russell AP 2004 Lipotoxicity: the obese and endurance-trained paradox. International Journal of Obesity and Related Metabolic Disorders 28 S66-S71.

Ryu JW, Kim MS, Kim CH, Song KH, Park JY, Lee JD, Kim JB \& Lee KU 2003 DHEA administration increases brown fat uncoupling protein 1 levels in obese OLETF rats. Biochemical and Biophysical Research Communications 303 726-731.

Sánchez J, Pérez-Heredia F, Priego T, Portillo MP, Zamora S, Garaulet M \& Palou A 2008 Dehydroepiandrosterone prevents age-associated alterations, increasing insulin sensitivity. Journal of Nutritional Biochemistry 19 809-818.

Saravanan N, Haseeb A, Ehtesham NZ \& Ghafoorunissa 2005 Differential effects of dietary saturated and trans-fatty acids on expression of genes associated with insulin sensitivity in rat adipose tissue. European Journal of Endocrinology 153 159-165.

Sjögren P, Sierra-Johnson J, Gertow K, Rosell M, Vessby B, de Faire U, Hamsten A, Hellenius ML \& Fisheret RM 2008 Fatty acid desaturases in human adipose tissue: relationships between gene expression, desaturation indexes and insulin resistance. Diabetologia 51 328-335.

Steinberg GR 2007 Inflammation in obesity is the common link between defects in fatty acid metabolism and insulin resistance. Cell Cycle 6 888-894.

Tagliaferro AR, Ronan AM, Payne J, Meeker LD \& Tse S 1995 Increased lipolysis to beta-adrenergic stimulation after dehydroepiandrosterone treatment in rats. American Journal of Physiology 268 1374-1380.

Takahashi Y \& Ide T 2000 Dietary $n-3$ fatty acids affect mRNA level of brown adipose tissue uncoupling protein 1 , and white adipose tissue leptin and glucose transporter 4 in the rat. British Journal of Nutrition 84 175-184.

Vessby B, Aro A, Skarfors E, Berglund L, Salminen I \& Lithell H 1994 The risk to develop NIDDM is related to the fatty acid composition of the serum cholesterol esters. Diabetes 43 1353-1357.

Waxman DJ 1996 Role of metabolism in the activation of dehydroepiandrosterone as a peroxisome proliferator. Journal of Endocrinology $\mathbf{1 5 0}$ S129-S147.

Wilding JP 2001 Leptin and the control of obesity. Current Opinion in Pharmacology 1 656-661.

Yanase T, Kukahori M, Taniguchi S, Nishi Y, Sakai Y, Takayanagi R, Haji M \& Nawata H 1996 Serum dehydroepiandrosterone (DHEA) and DHEAsulphate (DHEA-S) in Alzheimer's disease and in cerebrovascular dementia. Journal of Endocrinology 43 119-123.

Yaqoop P 2002 Monounsaturated fatty acids and immune function. European Journal of Clinical Nutrition 56 S9-S13.

\section{Received in final form 13 January 2009 \\ Accepted 13 January 2009 \\ Made available online as an Accepted Preprint 14 January 2009}

